\title{
Isolamento de Salmonella Braenderup em arara-azul (Anodorhynchus hyacinthinus)
}

\author{
Salmonella Braenderup isolation in Hyacinth macaw (Anodorhynchus hyacinthinus) \\ Mariangela Costa Allgayer ${ }^{I^{*}}$ Sérgio José de Oliveira ${ }^{\mathrm{I}}$ Vanessa Daniele Mottin ${ }^{\mathrm{I}}$ \\ Márcia Regina Loiko ${ }^{I}$ Fernanda Abilleira' ${ }^{I}$ Neiva Maria Robaldo Guedes ${ }^{\text {II }}$ \\ Daniel Thompsen Passos ${ }^{\mathrm{I}}$ Tania de Azevedo Weimer ${ }^{\mathrm{I}}$
}

\begin{abstract}
RESUMO
O monitoramento sanitário de populações de arara-azul (Anodorhynchus hyacinthinus) de vida livre visa a permitir ajustes de manejo em ambiente natural alterado. Para avaliar a ocorrência de Salmonella spp. em filhotes dessa espécie, foram coletados swabs de cloaca no Pantanal de Miranda, Mato Grosso do Sul (MS). Uma colônia morfológica e bioquimicamente compatível com Salmonella spp. foi isolada e sorotipada como Salmonella Braenderup. Devido ao alto potencial zoonótico desse microrganismo, é importante o controle sanitário de psitacídeos em vida livre. Na literatura pesquisada não foi encontrado relato sobre o isolamento dessa bactéria em arara-azul, tanto em vida livre, como em cativeiro.

Palavras-chave: Salmonella spp., Anodorhynchus hyacinthinus de vida livre, microbiota cloacal.
\end{abstract}

\section{ABSTRACT}

The sanitary monitoring of free-living Hyacinth macaw (Anodorhynchus hyacinthinus) allows adjusting the management in altered natural habitat. To evaluate the occurrence of Salmonella spp. it was collected cloacal swabs of this nestlings species, in the Pantanal wetlands, in the state of Mato Grosso do Sul, Brazil. One Salmonella-like colony was serologically typed and identified as Salmonella Braenderup. Due to the high zoonotical potential of this microorganism, it is important an effective sanitary control of wildlife psittacines. In the literature searched it was not found any report on isolation of this bacterium in Hyacinth macaw for both free-living and captive animals.

Key words: Salmonella spp., free-living Anodorhynchus hyacinthinus, cloacal microbiota.

A Salmonella é um microrganismo amplamente distribuído na natureza, tendo como reservatório aves e outros animais silvestres, com sorovares inespecíficos quanto ao hospedeiro, e sendo um dos mais importantes patógenos veiculados por alimentos. Pertence à família Enterobacteriaceae e está dividido nas espécies Salmonella enterica, $\boldsymbol{S}$. bongori (HOLT et al., 1994) e S. subterranea (SHELOBOLINA et al., 2004). A salmonelose aviária constitui um grupo de doenças agudas ou crônicas induzidas por Salmonella enterica, subespécie enterica, a qual pode ser dividida em três grupos: Pulorose, causada por Salmonella Pullorum; Tifo Aviário, causado por Salmonella Gallinarum; e Paratifo Aviário, causado por um grupo de diferentes sorovares de Salmonella enterica que estão relacionados também a infecções alimentares (BACK, 2002). Informações sobre a ocorrência e a distribuição de Salmonella spp. em animais silvestres e domésticos são essenciais para

ICentro Diagnóstico do Hospital Veterinário, Universidade Luterana do Brasil (ULBRA). Av. Farroupilha, 8001, prédio 25, 92425900, Canoas, RS, Brasil. E-mail: mallgayer@gmail.com.*Autor para correspondência.

"Instituto Arara-azul, Universidade para o Desenvolvimento do Estado e da Região do Pantanal (UNIDERP), Campo Grande, MS, Brasil. 
relacionar os possíveis reservatórios que possam ser responsáveis pela transmissão desse agente. Infecções alimentares têm sido descritas, tendo como agente causal a Salmonella Braenderup (TIBAIJUKA et al., 2003; GUPTA et al., 2007). DEVI \& MURRAY (1991) isolaram cinco sorovares de Salmonella spp., dentre eles, $S$. Braenderup, em baratas, ressaltando a importância de artrópodes na contaminação de alimentos. Aves clinicamente sadias e aquelas infectadas que sobreviveram a um surto podem ser portadoras de Salmonella spp. Desse modo, aves destinadas para programas de soltura e reintrodução ao ambiente natural, ou aves de produção, devem ser avaliadas quanto à presença desse microrganismo (CUBAS, 1993).

A arara-azul (Anodorhynchus hyacinthinus) é um dos psitacídeos brasileiros na lista de aves ameaçadas de extinção, e desde 1990 vários estudos estão sendo realizados com a população do Pantanal, resultando em uma série de conhecimentos adquiridos sobre essa espécie em seu ambiente natural (GUEDES et al., 2006; KUNIY et al., 2006; PIZO et al., 2008). Pesquisas sobre o monitoramento sanitário são de grande importância para a manutenção da saúde dessa espécie em vida livre. Dados microbiológicos de populações naturais podem contribuir para a conservação in situ e ex situ das espécies ameaçadas de extinção, estabelecendo os patógenos transmitidos pelo homem e por animais domésticos e permitindo ajustes no manejo em cativeiro ou em ambiente natural alterado.

Este trabalho relata o isolamento de Salmonella Braenderup em cloaca de arara-azul do Pantanal, em seu ambiente natural. O estudo foi realizado na sub-região de Miranda (1951'-1958'S e 56 $17^{\circ}-56^{\circ} 24^{\prime}$ W), no Pantanal do Mato Grosso do Sul, e foi aprovado pelo Comitê de Ética da Universidade Luterana do Brasil (ULBRA). Foram coletadas amostras da cloaca de 14 filhotes de arara-azul durante a estação reprodutiva, em dezembro de 2006, com swabs estéreis, armazenados em meio de "Stuart" e encaminhados ao Laboratório de Microbiologia do Hospital Veterinário da ULBRA, em Canoas, Rio Grande do Sul (RS). O material foi inoculado em placas contendo ágar-sangue e ágar McConkey, as quais foram incubadas em aerobiose por 24 horas, a $37^{\circ} \mathrm{C}$. As colônias com morfologia típica de Salmonella spp. foram submetidas a provas de triagem (ágar três-açúcares-ferro-TSI e ágar lisina-ferro-LIA), bioquímicas (uréia, fenilalanina, citrato e SIM) e aglutinação com soro somático polivalente. Quando confirmada a presença de Salmonella spp., a amostra foi transferida para Caldo Infusão Cérebro e
Coração (BHI) com glicerol, armazenada a $-18^{\circ} \mathrm{C}$ e enviada ao Laboratório de Enterobactérias da Fundação Oswaldo Cruz (FIOCRUZ) para sorotipificação.

Foi isolada Salmonella Braenderup em um filhote saudável; todos os indivíduos amostrados eram clinicamente sadios e voaram com sucesso no período esperado em torno 105-110 dias de idade (GUEDES \& HARPER, 1995). Na literatura compilada, não há registro, até o momento, do isolamento desse sorovar em arara-azul, tanto de vida livre, como em cativeiro, sendo esse dado importante no monitoramento sanitário da espécie estudada.

GOPEE et al. (2000) citam que aves de vida livre são apontadas como potenciais carreadoras de patógenos para o interior de plantéis de animais, mas que a frequência de Salmonella spp. em aves de cativeiro é relativamente baixa, quando comparada a mamíferos e répteis. No entanto, ALLGAYER et al. (2008) detectaram Salmonella spp. em 13\% dos psitacídeos sadios de cativeiro. BANGERT et al. (1988) isolaram $S$. Braenderup em aves de rapina criadas em cativeiro. Segundo OLMOS et al. (2006), aves de rapina podem ser consideradas carreadoras de patógenos. Essa hipótese pode ser considerada para explicar a contaminação do filhote, neste estudo, em virtude da nidificação de diferentes espécies de aves de rapina em ninhos utilizados pelas araras-azuis no Pantanal (GUEDES, 1993b; SILVAet al., 2005). VILELA et al.(2001) identificaram $S$. Bredeney em vísceras de um filhote, com 30 dias de idade, contribuindo para o esclarecimento do papel desse microrganismo como a causa da morte desse filhote. É possível que a contaminação tenha ocorrido pelo contato com os pais ao regurgitarem o alimento ou por via transovariana. Essa hipótese pode também ser aventada para explicar a ocorrência de $S$. Braenderup na presente amostra, e a ausência de sinais clínicos compatíveis com salmonelose, no presente caso, pode ter relação com a idade do animal (84 dias), pois, segundo GAST (2003), apenas em aves muito jovens as infecções por Salmonella spp. do grupo paratifóide estão associadas à doença. REAVILL (1996), por exemplo, relatou a ocorrência de surtos de Salmonella spp. em aves silvestres, sendo observada alta mortalidade apenas nos indivíduos jovens. Uma outra hipótese para a ocorrência de $S$. Braenderup neste animal poderia estar relacionada com os artrópodes associados aos ninhos. CARVALHO et al. (2006) descreveram a riqueza de táxons de artrópodes associada à serragem dos ninhos de arara-azul no Pantanal, evidenciando uma maior diversidade (70\% das morfoespécies identificadas) em ninhos artificiais. É importante salientar que, segundo GUEDES (1993a), um dos fatores limitantes da 
reprodução dessa espécie, no Pantanal, é a escassez de cavidades em árvores, além da disputa pelos ninhos com outras espécies de aves. Para minimizar esse fator limitante, o Projeto Arara Azul instalou ninhos artificiais, e as araras-azuis, bem como outras espécies que disputavam os ninhos naturais, passaram a ocupar os ninhos artificiais com sucesso (GUEDES \& HARPER, 1995). De acordo com CARVALHO et al. (2006), é necessário elucidar os fatores que podem afetar a relação da artropodofauna associada aos ninhos artificiais e naturais na população. Essa afirmação talvez seja relevante na epidemiologia da $S$. Braenderup, uma vez que esta foi isolada em um filhote nascido em ninho artificial. Estudos referentes ao isolamento de $S$. Braenderup em ninhos, artrópodes e outros animais que ocupam esses ninhos deverão ser incrementados para esclarecer a epidemiologia desse microrganismo na arara-azul e sua disseminação no meio ambiente.

Considerando-se o alto potencial zoonótico da Salmonella Braenderup, destaca-se a relevância do controle sanitário de psitacídeos em ambiente natural.

\section{AGRADECIMENTOS}

Este trabalho foi financiado pela Universidade Luterana do Brasil, pela Universidade para o Desenvolvimento do Estado e da Região do Pantanal, pelo Instituto Arara Azul, pelo Criadouro Asas do Brasil, pela Toyota do Brasil, pela WWF, pela Caiman, pela Brasil Telecom, pela Parrots International, Hyacinthine Macaw Survival Fund e pela Teresa Bracher.

\section{REFERÊNCIAS}

ALLGAYER, M.C. et al. Molecular diagnosis of Salmonella species in captive psittacine birds. Veterinary Record, v.162, n.25, p.816-819, 2008.

BACK, A. Manual de doenças de aves. Cascavel, PR: Alberto Back, 2002. 246p.

BANGERT, R.L. et al. A survey of the aerobic bacteria in the feces of captive raptors. Avian Diseases, v.32, n.1, p.53-62, 1988.

CARVALHO, T.D. et al. Artropodofauna associada a ninhos de Arara Azul no Pantanal de Miranda, Mato Grosso do Sul, Brasil. Bio (in) Formação, n.1, p.100-112, 2006.

CUBAS, S.Z. Natural diseases of free-ranging birds in South America. In: FOWLER, M.E. Zoo e wild animal medicine: current therapy, 3. Philadelphia: Saunders, 1993. p.166172 .

DEVI, S. J.; MURRAY, C. J. Cockroaches (Blatta and Periplaneta species) as resevoirs of drug-resistant salmonellas. Epidemiology and Infection, v.107, n.2, p.357-361, 1991. Disponível em: <http://journals.cambridge.org/action/ display Abstract?fromPage $=$ online $\&$ aid $=4707092>$. Acesso em: 20 jun. 2009. doi: 10.1017/S0950268800048998.

GAST, R.K. Salmonella infections. In: SAIF, Y.M. Diseases of poultry. 11.ed. Iowa: Iowa State University, 2003. p. 567614 .

GOPEE, N.V. et al. Retrospective and longitudinal study of salmonellosis in captive wildlife in Trinidad. Journal of Wildlife Disease, v.36, n.2, p.284-293, 2000.

GUEDES, N.M.R. Biologia reprodutiva da arara azul (Anodorhynchus hyacinthinus) no Pantanal-MS, Brasil. 1993a. 122f. Dissertação (Mestrado em Ciências Florestais) Universidade de São Paulo, Piracicaba, SP.

GUEDES, N.M.R. Nidificação do gavião-relógio (Micrastur semitorquatus) no Pantanal. In: CONGRESSO BRASILEIRO DE ORNITOLOGIA, 3., 1993, Pelotas, RS. Anais... Pelotas: UFPel, 1993b. p.53.

GUEDES, N.M.R; HARPER, L.H. Hyacinth macaws in the Pantanal: conservation and management. In: ABRAMSON, B.L. et al. The large macaws: their care, breeding and conservation. Fort Bragg, California: Raintree Publications, 1995. p.394-421.

GUEDES, N.M.R. et al. O uso do sistema de informação geográfica (SIG) em trabalhos de conservação das araras azuis e vermelhas no Pantanal Sul Matogrossense. Ensaio e Ciências, v.10, p.167-179, 2006.

GUPTA, S.K. et al. Outbreak of Salmonella Braenderup infections associated with Roma tomatoes, northeastern United States, 2004: a useful method for subtyping exposures in field investigations. Epidemiology and Infection, v.135, n.7, p.1165-73, 2007. Disponível em: <http://journals.cambridge.org/action/ displayAbstract ?fromPage $=$ online $\&$ aid $=1344844>$. Acesso em: 19 jun. 2009. doi: 10.1017/S0950268807007911.

HOLT, J.G. et al. Bergey's manual of determinative bacteriology. 9.ed. Baltimore: William \& Wilkims, 1994. $787 \mathrm{p}$.

KUNIY, A.A. et al. Handling technique to increase the hyacinth macaw population (Anodorhynchus hyacinthinus) (Lalham, 1720) - report of an experience in Pantanal, Brazil. Brazilian Journal of Biology, v.66, p.381-382, 2006. Disponível em: $<$ http://www.scielo.br/scielo.php?script=sci_arttext\&pid=S151969842006000200021\&lng=en \&nrm= so>. Acesso em: 19 jun. 2009. doi: 10.1590/S1519-69842006000200021.

OLMOS, F. et al. Notas sobre aves de rapina (Cathartidae, Acciptridae e Falconidae) brasileiras. Revista Brasileira de Ornitologia, v.14, n.4, p.401-404, 2006.

PIZO, M.A. et al. Conservation puzzle: endangered hyacinth macaw depends on its nest predator for reproduction. Biological Conservation, v.141, p.792796, 2008. Disponível em: <http://www.sciencedirect.com/ science?_ob=ArticleURL\&_udi=B6V5X4S02TFY1\&_user=10\&_rdoc=1\& $\_\mathrm{fmt}=\&$ \&orig=search $\&$ _sort $=\mathrm{d} \& \mathrm{view}=\mathrm{c} \& \_$acct $=\mathrm{C} 00005$ $0221 \&_{\text {_version }}=1 \&_{\text {__ url }}$ Version $=0 \&$ _userid $=1$ $0 \& m d 5=4804$ e66ba526a5b0be890dcde716a2f3 $>$. Acesso: 19 jun. 2009. doi: 10.1016/j.biocon.2007.12.023. 
REAVILL, D. Bacterial diseases. In: ROSSKOPF, W.; WOERPEL, R. Diseases of cage and aviary birds. Baltimore: Williams \& Wilkins, 1996. p.600-605.

SHELOBOLINA, E.S. et al. Isolation, characterization, and U (VI) reducing potencial of a facultatively anaerobic, acid-resistant bacterium from low-pH, nitrato-and U (VI) - contaminated subsurface sediment and description of Salmonella subterranea sp. Nov. Applied and Environmental Microbiology, v.70, n.5, p.2959-2965, 2004. Disponível em: <http://aem.asm.org/cgi/ content $/$ full/70/5/2959? maxtoshow $=\&$ HITS $=10$ \&hits $=10 \& R E$ $\mathrm{S}$ U L T F O R M A T = \& a u t h o r $1=\mathrm{S}$ HELOBOLINA \& searchid $=1 \&$ FIRSTINDEX $=0 \&$ fdate $=5 / 1 /$ 2004\&tdate $=5 / 31 / 2004 \&$ resourcetype $=$ HWCIT $>$. Acesso em: 19 jun. 2009. doi: 10.1128/AEM.70.5.2959-2965.2004.
SILVA, G.F. et al. O uso de ninhos naturais e artificiais monitorados pelo projeto arara azul em 2004 no Pantanal-MS. In: ENCONTRO DE BIÓLOGOS DO CRBio-1, 16., 2005, Campo Grande, MS. Resumos... Campo Grande: Conselho Regional de Biologia - 1Região, 2005. p.57.

TIBAIJUKA, B. et al. Occurrence of Salmonellae in retail raw chicken products in Ethiopia. Berliner und Munchener Tierarztliche Wochenschrift, v.116, n.1-2, p.55-58, 2003.

VILELA, V.O. et al. Salmonella Bredeney em Arara-Azul (Anodorhynchus hyacinthinus). In: STRAUB, F.C. Ornitologia sem fronteiras. Curitiba: Fundação O Boticário, 2001. p.390-391. 